\title{
The Research on Force Condition Checking Calculation of the Girder in Construction with Bridge Girder Erection Machine
}

\author{
Er-Yu ZHU ${ }^{1, a^{*}}$, Hong-Liang WANG ${ }^{2, b}$, Shi-Guang MA ${ }^{3, c}$ \\ ${ }^{1,2}$ School of Civil Engineering, Beijing Jiaotong University, Beijing 100044, China \\ ${ }^{3}$ China Railway Sixth Group Shijiazhuang Railway Construction, Co, Itd 050500 \\ aeyzhu@bjtu.edu.cn, bwhl.981@163.com, ' $m s g 100 @ 126 . c o m$ \\ ${ }^{*}$ Corresponding author
}

Keywords: Bridge across the Railway, Bridge Girder Erection Machine, Checking Calculation of the Girder in Construction.

\begin{abstract}
In this paper, combined with the construction of a highway bridge across the railway Beijing-Guangzhou, discusses how to check the process of the construction with bridge girder erection machine. The contents of the bridge construction which need to be calculated are checked according to the characteristics of the structure and construction machine, and the stress state of the structure in construction is gotten, which can provide the theory support for the girder construction.
\end{abstract}

\section{Introduction}

With the constant improvement of railway and highway transportation system in China, railway and highway mileage have been raised sharply, and the transport networks have become increasingly complex in China. In the transportation route planning, there will be more and more intersection between the roads and railways, as the artery of national economy, to ensure the railway in normal operation is priority than other things. So the research on force condition checking calculation of the girder in construction with bridge girder erection machine is very important to ensure the safety of the railways. This paper introduces the research work on force condition checking calculation of the girder in construction with bridge girder erection machine which based on the girder construction of the bridge of an expressway across the Beijing-Guangzhou railway [1-6].

\section{The Structure of Bridge Girder Erection Machine}

The bridge girder erection machine of type GT40/130 was used in the erection of the bridge girder. The transverse coupling systems and diagonal bridging should be installed in the front, middle and back between the two Longitudinal beams of bridge girder erection machine to ensure stability and firm. The structure is shown in Fig.1.

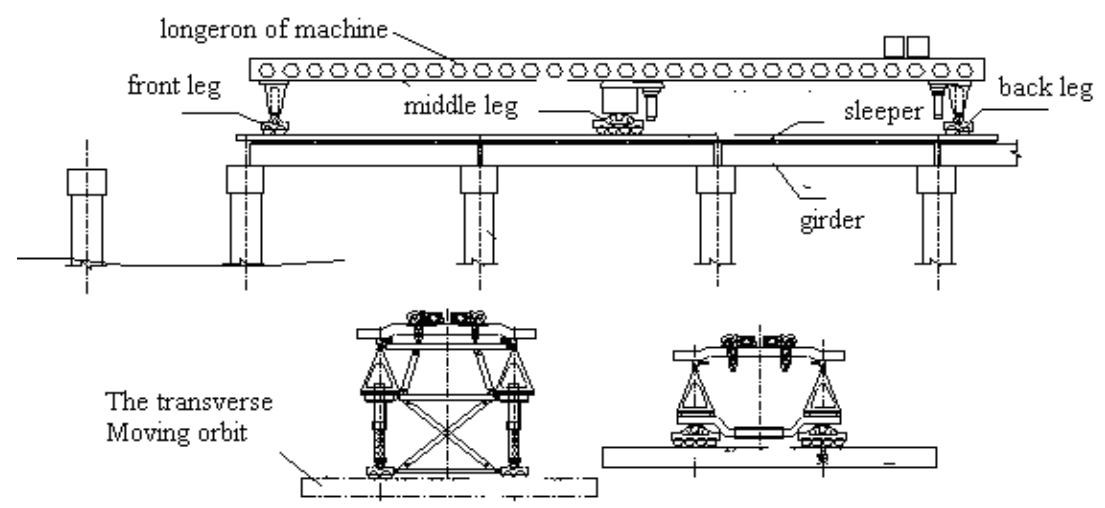

Fig. 1 The Structure of the Bridge Girder Erection Machine 


\section{The Contents of Checking Calculation of the Girder in Construction}

First of all, a theoretical calculation of girder construction system for theoretical data should be carried out. According to the characteristics of the project and the structure of the bridge machine, the following contents in construction which are need checked are identified:

(1)Load-carrying capability of the girder should be checked calculated in construction

(2)Load-carrying capability of the pier should be checked calculated in construction

(3) The safety check calculation of crossing a span in the cantilever gesture should be checked

(4) The safety check calculation of the lateral movement orbit in the construction of side span beam should be checked

\section{The Checking Calculation on the Load-carrying Capability of the Girder}

In the construction stage, the simply supported girders will bear loads settled by the bridge girder erection machine, so in this condition the load-carrying capability of the simply supported girder should be checked in order to meet the requires of the construction. This condition is shown in Fig.2

There are two kinds of loads should be taken into account: concentrated load and uniformly distributed load.

1) Under the action of concentrated load

All the girders are simply supported in construction stage, when the loads of bridge girder erection machine located in the middle of the $35 \mathrm{~m}$ span is the most unfavorable condition.

$\mathrm{P}=295.29 \mathrm{kN}$

Tab. 1 Beam Stress Table under the Concentrated Load

\begin{tabular}{|c|c|c|c|c|}
\hline \multicolumn{2}{|c|}{ Bending moment M (kN.m) } & \multicolumn{3}{|c|}{ Stress (MPa) } \\
\hline Position & $\begin{array}{c}\text { Bending moment } \\
\text { of section }\end{array}$ & Position & $\begin{array}{c}\text { Top of } \\
\text { section }\end{array}$ & $\begin{array}{c}\text { Bottom of } \\
\text { section }\end{array}$ \\
\hline Middle of span & 2478.2 & Middle of span & 9.23 & -0.92 \\
\hline
\end{tabular}

2) Under the action of uniformly distributed load.

The edge beams are expressed as uniformly distributed load, which located at the middle span of $35 \mathrm{~m}$ girders and the side span of $22 \mathrm{~m}$ girders.

$\mathrm{P}($ side girder $)=1020 \mathrm{kN}$

$\mathrm{q}=1020 /(4 \times 35)=7.5 \mathrm{kN} / \mathrm{m}$

Tab. 2 Beam Stress Table under Uniformly Distributed Load

\begin{tabular}{|c|c|c|c|c|}
\hline \multicolumn{2}{|c|}{ Bending moment M(kN.m) } & \multicolumn{3}{|c|}{ Stress (MPa) } \\
\hline Position & $\begin{array}{c}\text { Bending } \\
\text { moment of } \\
\text { section }\end{array}$ & Position & $\begin{array}{c}\text { Top of } \\
\text { section }\end{array}$ & $\begin{array}{c}\text { Bottom of } \\
\text { section }\end{array}$ \\
\hline Middle of span & 1385.01 & Middle of span & 7.51 & 1.83 \\
\hline
\end{tabular}

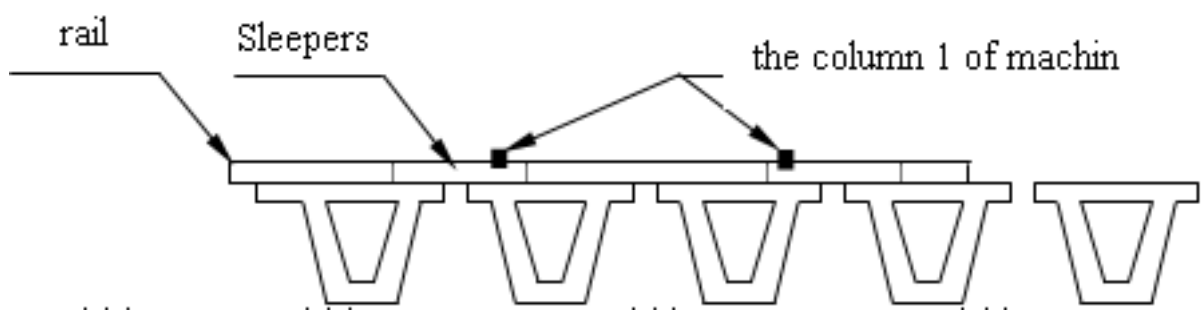

Fig. 2 The Diagram when Bridge Crane over Hole 
The calculation result shows that the load-carrying capability of the girder can meet the requirements of the erection construction. But it is important to note that load of bridge girder erection machine should be settled by the four pieces of beams to ensure that the load of each beam does not exceed $1 / 3$ of the total weight.

\section{The Checking Calculation on the Load-carrying Capability of the Pier}

It does not need to carry on the checking calculation if beam erection on double column piers. But pier will be in a state of eccentric compression if beam erection on single column pier. The most adverse state of eccentric compression is in the erection condition of 3 and 1 piece of girder. The calculation was carried on and the result shows that the load-carrying capability of the pier can meet the requirements of the construction.

\section{The Safety Check Calculation of Crossing a Span in the Cantilever Gesture}

1) The weight of different parts:

W1 - the weight of front leg, $4.2 / 2=2.1 \mathrm{t}=21 \mathrm{kN}$

$\mathrm{W} 2$ - the weight of transverse guide beam, $4.9+1.5 \times 2+6=13.9 \mathrm{t}=139 \mathrm{kN}$

$\mathrm{q}$ - uniformly distributed load, $5 \mathrm{kN} / \mathrm{m}$

Q - the weight of beam, $100 / 2=50 \mathrm{t}=500 \mathrm{kN}$

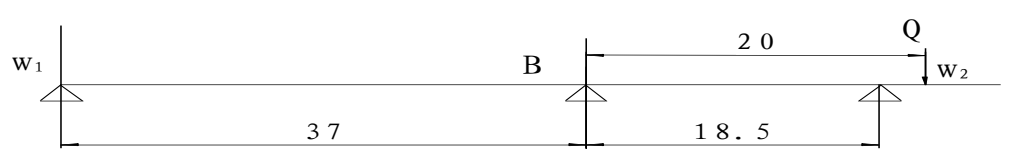

Fig. 3 Force Diagram when Bridge Crane over Hole

2) Overturning moment:

$$
\mathrm{Mq}=\mathrm{W} 1 \times 37+\mathrm{ql} 2 / 2=2.5 \times 37+0.5 \times 38.52 / 2=463 \mathrm{~mm}=4630 \mathrm{kN} . \mathrm{m}
$$

3) Equilibrium moment:

When $\mathrm{RB}=0$,

$\mathrm{Mp}=18.5 \times \mathrm{W} 2 / 2+\mathrm{q} 12 / 3+(\mathrm{Q}+\mathrm{W} 2 / 2) \times 20$

$=18.5 \times 6.95+0.5 \times 26.52 / 2+56.95 \times 20=1443 \mathrm{~m}=14430 \mathrm{kN} . \mathrm{m}$

4) Stability factor:

$$
\mathrm{n}=\mathrm{Mp} / \mathrm{Mq}=14430 / 4630=3.1>1.3
$$

\section{The Safety Check Calculation of the Lateral Movement Orbit in the Construction of Side Span Beam}

1) The cantilever size of lateral movement orbit on the position of front and middle strong point:

The distance between centers of concrete beam and column is $900 \mathrm{~mm}$, the wheel center $800 \mathrm{~mm}$.

Front strong point: the distance between mat stone and the edge of capping beam: $500 \mathrm{~mm}$; the cantilever of walk road wheel $800 \mathrm{~mm}$.

Middle strong point: the width of web: $1800 \mathrm{~mm}$; the cantilever of walk road wheel: $400 \mathrm{~mm}$

2) Moment of inertia of orbital:

Front strong point: $\mathrm{W}=1471.6 \mathrm{~cm} 3$

Middle strong point: $\mathrm{W}=1073.4 \mathrm{~cm} 3$

3) The force on the position of front and middle strong point:

The weight of bridge girder erection machine: $1000 \mathrm{kN}$, the force in Front Strong point: 300kN, the force in middle Strong point: $700 \mathrm{kN}$ 
Front Strong point: $690 \mathrm{kN}$ (single column), $345 \mathrm{kN}$ (single wheel); middle Strong point: $101 \mathrm{kN}$ (single column); $505 \mathrm{kN}$ (single wheel)

4) The bending moment of the cantilever in the position of Front and middle Strong point

Front Strong point: $\mathrm{M}=345 \times 0.8=276 \mathrm{kN} \cdot \mathrm{m}$;

Middle Strong point: $\mathrm{M}=505 \times 0.4=202 \mathrm{kN} \cdot \mathrm{m}$

5) Stress:

Material allowable stress: $[\sigma]=210 \mathrm{MPa}$

Front Strong point: $\sigma=27.6 \times 104 / 1471.6=187.6 \mathrm{MPa}<210 \mathrm{MPa}$

Middle Strong point: $\sigma=20.2 \times 104 / 1073.4=188.2 \mathrm{MPa}<210 \mathrm{MPa}$

\section{Summary}

In this paper, the checking content of girder erection is introduced by combing with the checked calculation of actual project, and through calculation and test, the conclusion is as follows:

(1)Load-carrying capability of the girder is checked calculated in construction

(2)Load-carrying capability of the pier is checked calculated in construction

(3) The safety calculation for crossing a span in the cantilever gesture should be checked.

(4) The safety calculation for the lateral movement orbit in the construction of side span beam should be checked.

The checked results show that the index can conform to the requirements of the girder construction. The work will provide a valuable reference for other girder construction with bridge girder erection machine.

\section{Acknowledgement}

The authors wish to acknowledge the support and motivation provided by Science and Technology Research and Development Plan of Railway Ministry (No.2012G002-5), Specialized Research Fund for the Doctoral Program of Higher Education of China (No.20110009110016), Science and Technology Research and Development Plan of China Railway Corporation (No.Z2013-G004).

\section{References}

[1]Jing De Hou, De Xue Yin. DF50/150 type bridge frame beam construction technology. Railway construction technology, 2000, (4):8-10.

[2]Li HuaJiang. The railway bridge frame beam regulation (TB10213-99) revised profile. Railway standard design, 2001(3):27.

[3]Jian Zhong Wang. Rail transit line no. $16 \mathrm{u}$-shaped girder erection construction technology. Urban road and bridge and flood control, 2012(8):258-259.

[4]Shun Xi Zhou. Lift girder construction technology. Engineering and technology: 212-213.

[5]Qing Chen. The application of bridge girder erection machine in the open highway bridge girder construction. Urban road and bridge and flood control, 2008(7), 95-97.

[6]Feng Wang. Construction technique of girder erction with bridge girder erection machine TLJ 900 while passing through tunnel on Shijiazhuang-Taiyuan railway passenger dedicated line. Journal of railway engineering society, 2007(12), 270-273. 